$(10,72 \%)$ e doenças metabólicas $(8,9 \%)$. A maior parte dos animais incluídos neste estudo vivia fora de casa $(62 \%)$, contudo, não houve diferença significante na sobrevida dos animais criados dentro e fora de casa. Por outro lado, animais considerados obesos pelos seus proprietários, viveram menos ( 5 anos e 7 meses) que os não obesos ( 8 anos e 9 meses). Os resultados deste trabalho permitem concluir que a longevidade média dos animais na cidade de São Paulo foi menor que a descrita para outros paises. Animais sem raça definida viveram mais que animais com raça determinada, enquanto que animais castrados tiveram maior sobrevida que os não castrados. Entre os não castrados, as fêmeas tiveram maior longevidade que os machos e animais de pequeno porte e gigantes viveram por menos tempo que os de médio e grande porte.

\title{
55 - Características clínico-epidemiológicas do hiperadrenocorticismo na região de Botucatu - SP
}

Aptekmann, K.P.'; Peixoto, A.S.'; Altwegg, D.'; Vicente, P.C.'; Schwartz, D.S. ${ }^{2}$
1- Residente de Clínica Médica de Pequenos Animais da Faculdade de Medicina Veterinária e Zootecnia da Universidade Estadual Paulista, Campus de Botucatu, Botucatu-SP

2-Professora Assistente Doutora do Departamento de Clínica Veterinária da Faculdade de Medicina Veterinária e Zootecnia da Universidade Estadual Paulista, Campus de Botucatu, Botucatu-SP

O hiperadrenocorticismo (HAC) é um distúrbio associado ao excesso de glicocorticóides endógenos ou exógenos, sendo uma das endocrinopatias mais comuns em cães, raramente diagnosticado em gatos. O HAC espontâneo ocorre devido ao aumento da secreçào endógena de cortisol, podendo ser hipófise ou adrenal-dependente. Quando o HAC resulta de causas exógenas, é referido como iatrogênico. Este trabalho objetiva mostrar a prevalência da doença na região de Botucatu-SP, evidenciando os dados de resenha, exames laboratoriais e os principais sintomas apresentados. Foi feito um levantamento entre janeiro de 1998 a abril de 2003, no Hospital Veterinário da FMVZ - Unesp, no qual foram obtidos 15 animais, sendo todos cães, com testes endócrinos que confirmaram o diagnóstico. Entretanto, outros cães com suspeita da doença não foram incluídos neste estudo por falta de teste endócrino confirmatório. Quanto às raças, o Poodle $(33 \%)$ e os animais sem raça definida $(26 \%)$ foram os mais comuns. Outras raças acometidas foram Maltês, Boxer, Akita, Pinscher, Teckel e Fox Paulistinha. A idade variou entre 4 e 12 anos, com média de 8 anos, sendo que $53 \%$ eram fêmeas e $47 \%$ eram machos. Em ordem de maior ocorrência, os sinais clínicos foram poliúria, polidipsia, polifagia, distensão abdominal, cansaço fácil, apatia, alterações dermatológicas (rarefaçào pilosa, discromia, calcinose cutânea, mapeamento vascular, verrugosidades), ganho de peso, hepatomegalia, dispnéia, pele adelgaçada, anestro, dificuldade locomotora, anorexia e vômito. Os achados mais comuns no hemograma foram linfopenia, eosinopenia, neutrofilia e monocitose, compativel com um hemograma de estresse, comum nos cães que apresentam HAC. Apenas um animal apresentou leucopenia com anemia macrocítica hipocrômica, não estando relacionado com HAC. A contagem de plaquetas estava elevada em $26 \%$ dos animais e o restante apresentou valores normais. A urinálise revelou densidade isostenúrica em 8 animais e hipostenúrica em 2; a infecção do trato urinário esteve presente em todos os animais que realizaram urinálise. No bioquímico foi constatado um aumento das enzimas hepáticas (ALT, FA, GGT) em todos os animais avaliados. Foi verificado que 2 animais apresentavam hiperglicemia, glicosúria e cetonúria, caracterizando um quadro de diabetes mellitus associado. O perfil renal mostrou-se alterado somente em um animal. Três animais apresentaram valores de colesterol dentro dos limites de normalidade e 9 apresentaram um aumento do mesmo. O exame ultrassonográfico foi realizado $\mathrm{em} 7$ càes, o qual evidenciou aumento das adrenais bilateral $\mathrm{em}$ um caso e aumento unilateral em dois casos, além de degeneração gordurosa em todos os animais em que o exame foi realizado. Para o diagnóstico definitivo de hiperadrenocorticismo foi realizado o teste de supressão com dexametasona, sendo que 2 cães apresentaram teste sugestivo de HAC adrenal-dependente e o restante hipófise-dependente. Apenas em um animal não foi realizado 
o teste, pois este apresentava histórico de administração exógena de corticóide, sugerindo-se um quadro de $\mathrm{HAC}$ iatrogênico. Atualmente, a ocorrência do HAC tem aumentado na clínica de pequenos animais, tornando-se essencial inclui-lo nos diagnósticos diferenciais de outras endocrinopatias, além de outras causas de poliúria e polidipsia, como doenças renais e hepáticas. Para isso, é importante o reconhecimento da doença e sua predisposição.

\section{6 - Emprego do bezafibrato no tratamento da hipertrigliciridemia primária em Schnauzer. Relato de dois casos}

Jericó, M. M.'; Maschietto, L. A. ${ }^{2}$
1- Clínica Veterinária Alto da Lapa da Universidade de Santo Amaro, Universidade Bandeirantes e AnhembiMorumbi, São Paulo-SP

2- Clínica Veterinária Alto da Lapa, Pet Blue, São Paulo-SP

A hiperlipidemia é o termo usado para descrever a concentração excessiva de colesterol ou de triglicérides no soro ou plasma de animal em jejum. É o resultado direto do aumento na produçào de lipoproteínas ou da redução da degradação destas moléculas. $\mathrm{O}$ estado de hiperlipidemia é caracterizado como primário (ou familiar) ou secundário à doença endócrina metabólica. A hiperlipidemia por excesso de concentração de triglicérides é a forma grave de distúrbio no transporte lipídico em cães. A hipertrigliceridemia não apenas sinaliza a presença de distúrbio metabólico subjacente, mas é fator de risco importante para a saúde do paciente, $\mathrm{e}$, justifica a intervenção dietética $\mathrm{e} / \mathrm{ou}$ terapêutica. Os cães afetados estão sob o risco de desenvolver pancreatites, convulsões e distúrbios gastro intestinais. O mecanismo exato não foi elucidado, mas é provável que a diminuição da atividade da lipase lipoprotéica ou, ainda, a ausência da apoproteina C II de superfície estejam relacionadas ao acúmulo de triglicérides na circulaçào. Relatos prévios sugerem que animais da raça schnauzer adultos ou idosos estejam predispostos a hiperlipidemia primaria ou familiar, não associada a distúrbios endócrinos subjacentes. A restrição de gordura dos alimentos é a primeiro passo do tratamento, por meio da utilização da dieta com porcentagem de gordura menor que $10 \%$ da matéria seca. Como coadjuvante, nos casos em que a dieta não se mostra eficaz, pode-se utilizar as drogas hipolipidemiantes, a exemplo do bezafibrato, do grupo dos fibratos. Estes são capazes de diminuir os niveis séricos de colesterol, de triglicérides (notavelmente VLDL e LDL), além de reduzir as concentrações de fibrinogênio. Adicionalmente, propiciam a elevação dos níveis séricos de HDL. São eficazes na maioria dos tipos de dislipidemias, tanto primárias quanto secundárias. O mecanismo molecular na qual o bezafibrato reduz o depósito de gordura na célula não foi completamente elucidado. Sabe-se que ele é responsável pelo aumento na degradaçào de ácidos graxos, reduzindo a capacidade de sintetizar os triglicerideos. Não existem relatos publicados sobre o uso desta droga em animais da espécie canina em toda a literatura compilada. Objetivou-se avaliar a eficácia do benzafibrato em càes que apresentavam aumento do nível de triglicérides plasmático e que não responderam à terapia nutricional instituída. No presente trabalho, realizado na Clínica Veterinária Alto da Lapa, foram selecionados dois animais da raça schnauzer, sendo um macho, oito anos, não castrado (cão 1) e, o outro, uma fêmea, 12 anos, não castrada (cão 2), que apresentaram hipertrigliceridemia mesmo após a utilização prolongada de dieta hipocalórica, com baixos niveis de gordura e altos teores de fibra. Os valores de triglicérides pré-terapia com o bezafibrato foram iguais a $891 \mathrm{mg} / \mathrm{dl}$ (cão 1) e $4398 \mathrm{mg} / \mathrm{dl}$ (cão 2). Foi administrado o bezafibrato na dose de $2,5 \mathrm{mg} / \mathrm{kg}$, a cada 12 horas, e após 90 dias do início do tratamento os valores de triglicérides foram iguais a $306,2 \mathrm{mg} / \mathrm{dl}$ (cão 1) e $419 \mathrm{mg} / \mathrm{dl}$ (cão 2). Ao longo do período, o uso do medicamento não resultou em efeitos deletérios ao perfil hematológico $\mathrm{e}$ às funções renal e hepática, como constado pelas realizações mensais de hemograma completo, além das determinações séricas de uréia e creatinina, de ALTe FA. Concluímos que, para o controle da hipertrigliceridemia primária em cães da raça schnauzer, o bezafibrato se mostrou eficaz e, aparentemente, sem efeitos colaterais. 